\title{
Inactivation of Baroduric Bacteria Isolated by High Hydrostatic Pressure from Pickled Cowpea
}

\author{
Xuemei $\mathrm{Li}^{1}$, Dong Zhao ${ }^{1}$, Anjun Chen ${ }^{1}$, Tiantian $\operatorname{Lin}^{2} \&$ Biao $\mathrm{Pu}^{1}$ \\ ${ }^{1}$ College of Food Science, Sichuan Agricultural University, Yaan, China \\ ${ }^{2}$ College of Forestry, Sichuan Agricultural University, Yaan, China \\ Correspondence: Biao Pu, College of Food Science, SichuanAgricultural University, Yaan 625014, China. Tel: \\ 86-139-0816-0854. E-mail: pubiao2002@yahoo.com.cn
}

Received: April 19, 2012 Accepted: May 8, 2012 Online Published: May 29, 2012

doi:10.5539/jfr.v1n3p101 URL: http://dx.doi.org/10.5539/jfr.v1n3p101

The research was supported by the Project of National Natural Science Foundation of China (No.31171726) and the Technology Support Project of Sichuan Province (No.2010NZ0045)

\begin{abstract}
In this study, Pickled Cowpea, a typical lactic acid fermented vegetable in Sichuan, China, was used as samples to study both species and inactivation of baroduric bacteria isolated by HHP treatment under different pressure levels and different pressure holding time. 16S rDNA gene sequence, amplified using genomic DNA of 4 baroduric bacteria from Pickled Cowpea as templates, were sequenced and then were identified based on the sequence similarity and homology analysis, as B. licheniformis, B. subtilis, B. sonorensis and B. pumilus. The pressure resistance of the 4 strains are compared under pressure from 300 to $500 \mathrm{MPa}$ with holding time from 3 to $25 \mathrm{~min}$. B. pumilus which has higher pressure resistance can be selected as indicator bacteria for applying HHP treatment to Pickle production.
\end{abstract}

Keywords: high hydrostatic pressure, baroduric bacteria, isolation, identification, pickled cowpea

\section{Introduction}

Fermentation, a centuried food preservation technology, can naturally prolong the shelf life of vegetable and improve its safety, nutrition and sensory quality. Pickle, a traditional fermented food in China as one of the 4 most popular fermented vegetable in Sichuan, is produced by salt hypertonic effect and lactic acid fermentation. Because of various flavor and nutriment created during fermentation, Pickle has abilities such as regulating intestinal microflora and lowering cholesterol level (Yang et al., 1996). Being popular for unique flavor and nutritional value in China, Pickled Cowpea is selected as research material in this study. Generally speaking, Lactic acid bacteria, growing during the lactic acid fermentation, can inhibit the growth of other microorganisms. Nevertheless, due to effect of microorganisms and enzymes which including breeding of spoilage bacteria in industrial production, shelf life was greatly shortened while quality was reduced (Song et al., 2004; Cheigh \& Park, 1994). Thermal sterilization, especially pasteurization around 80 degrees Celsius, which is widely applied to Pickle nowadays for increasing its shelf life (Zhong, Li, \& Xu, 2008), has a disadvantage that the quality of Pickle will be influenced, because the inter-atomic forces of small molecular compound such as pigment, flavor and vitamin in pickled vegetable will be broken (Wu, Yu, \& Li, 1999). Therefore, new ways of sterilization, which both extend shelf life and maintain the original quality as far as possible, are requested by modern industrial production.

High hydrostatic pressure (HHP) technology, one of the emerging non-thermal sterilization techniques, not only inactivate microorganisms and spores but also maintain the original special flavor and nutritional quality, by utilizing isostatic pressure to affect cell membranes of microbes, nucleic acid of microbes, and the protein conformations (Meyer et al., 2000; Trujillo et al., 2000; Hartmann, Mathmann, \& Delgado, 2006). Although applications of HHP have been lucubrated on kinds of food like juice and jam, even HHP-treated juice has already faced to market; research on HHP technology of fermented vegetables is lack at present. Generally speaking, HHP technology can effectively improve safety and quality of fermented vegetable in industrial production, but due to differences in raw materials, fermented methods and regionalism, inactivation of 
microorganisms caused by HHP treatment are very different.

Kuribayashi et al. (1996) reported that microorganisms in Nozawana-zuke (a fermented vegetable from Japan) were obviously killed at pressure level between $300 \mathrm{MPa}$ and $400 \mathrm{MPa}$ for 10 min holding time, so that shelf life was extended without affecting the texture, color and flavorat the same time. By reducing quantity of Lactobacillus plantarum by $6 \log$ units at $400 \mathrm{MPa}$ for $10 \mathrm{~min}$, the Kimchi samples can be stored for 4 weeks at $20{ }^{\circ} \mathrm{C}$. Furthermore, the excessive acidification of Kimchi during storage can be restrained by over $400 \mathrm{MPa}$ HHP treatment (Sohn \& Lee, 1998). Peñas et al. (2010) reported that the magnitude of microorganisms in sauerkraut was reduced by 4 to $5 \log _{10}$ CFU/g when HHP-treated, in the same time colony counts of mesophilic bacterium and Lactobacillus were significantly decreased.

Sterilizing effect of Pickled Cowpea caused by HHP treatment has not been studied, where the key problem is to confirm target bacterium when applying HHP technology to Pickled Cowpea. In this thesis, the residuary baroduric bacteria and inactivation on different pressure levels and holding time is investigated, in order to establish basic instructions for HHP researches on Pickle.

\section{Materials and Methods}

\subsection{HHP on Pickled Cowpea Samples}

Pickled Cowpea samples for the experiment were provided by Liji Pickles and Condiment Co. Ltd., a famous commercial pickled vegetable productor, located in Sichuan, China. The samples, with $\mathrm{pH}$ 3.8-4.0 and 1.3\% salt content, were selected randomly from two parallel batches, which were desalted and sliced on the production line after mature fermented in the fermentation pits, without mixing condiment or heating for pasteurization, and then were vacuum-packed promptly by polyethylene bags ( $25 \mathrm{~g}$ /package, $-0.1 \mathrm{MPa}$ vacuum degree) for being stored at $4{ }^{\circ} \mathrm{C}$.

The equipment in our experiment is a hydrostatic pressurization unit (RL-003, WenzhouBeinuo Co., Ltd., Zhejiang, China), which use distilled water as the pressure-transmitting fluid. Packaged samples were exposed to $600 \mathrm{MPa}$ hydrostatic pressure for $25 \mathrm{~min}$ at room temperature $\left(20^{\circ} \mathrm{C}\right)$, to kill common bacteria except baroduric bacteria. The rising rate of pressure is approximately $150 \mathrm{MPa} / \mathrm{min}$, and the pressure relief process is nearly instantaneous $(\leq 2 \mathrm{~s})$.

\subsection{Isolation and Purification of Baroduric Bacteria}

Each HHP-treated sample was homogenized in $225 \mathrm{~mL}$ of sterile $0.85 \% \mathrm{NaCl}$ solution for $2 \mathrm{~min}$, in order to use aerobic plate count method to detect viable bacteria. Samples were serial diluted with sterile $0.85 \% \mathrm{NaCl}$ solution to appropriate dilution ratio, and then $1.0 \mathrm{ml}$ diluted sample was sucked and injected into plate count agar (PCA, composition: tryptone $5.0 \mathrm{~g} / \mathrm{L}$, yeast extract $2.5 \mathrm{~g} / \mathrm{L}$, glucose $1.0 \mathrm{~g} / \mathrm{L}$, agar $15.0 \mathrm{~g} / \mathrm{L}, \mathrm{pH} 7.0 \pm 0.2$, autoclaving at $121{ }^{\circ} \mathrm{C}$ for $20 \mathrm{~min}$ ) to detect the viable counts of aerobic plate count. After incubating the plates at $37{ }^{\circ} \mathrm{C}$ for $48 \pm 2 \mathrm{~h}$, the typical colonies were picked out. Isolation of bacteria was implemented by repeatedly plate streaking on nutrient agar (NA, composition: peptone $10.0 \mathrm{~g} / \mathrm{L}$, beef extract $3.0 \mathrm{~g} / \mathrm{L}, \mathrm{NaCl} 5.0 \mathrm{~g} / \mathrm{L}$, agar $17.0 \mathrm{~g} / \mathrm{L}$, $\mathrm{pH} 7.2 \pm 0.2$, autoclaving at $121{ }^{\circ} \mathrm{C}$ for $20 \mathrm{~min}$ ) until pure cultures of single strain were obtained. The nutrient agar wasalso used for preserving strains.

\subsection{Identification of Baroduric Bacteria}

Gram Stain and microscopic examination were used in preliminary observation of bacterial stains, and $16 \mathrm{~S}$ rDNA sequence analysis was used to identify residuary baroduric bacteria. Genomic DNA of strains were extracted as template, by genomic DNA extraction reagent kit of bacteria (SK8225, Sangon Biotech (Shanghai) Co. Ltd., China), then the 16S rDNA sequences were performed by employing universal primer of bacteria, including forward primer P1 (5'-AGAG TTT GAT CCT GG TCA GA ACG CT-3, 40 pmol) and reverse primer P6 (5'-T ACG GCT ACC TTG TTA CGA CTT CAC CCC-3', 40 pmol) for polymerase chain reaction (PCR) amplification, according to Jin et al. (2011). PCR reactions were performed in a total volume of $50 \mu \mathrm{L}$ using a final concentration of $25 \mu \mathrm{L} 2 \times$ Taq PCR MasterMix, $2.0 \mu \mathrm{L}$ P1, $2.0 \mu \mathrm{L}$ P6, $2.0 \mu \mathrm{L}$ DNA templates $(50 \mathrm{ng} / \mathrm{mL})$ and $19 \mu \mathrm{L}$ double distilled water. P1 and P6 were synthesized by Sangon Biotech (Shanghai) Co. Ltd. while $2 \times$ Taq PCR MasterMix (KT201-01) was made by Tiangen Biotech (Beijing) Co. Ltd. PCR conditions were: $92{ }^{\circ} \mathrm{C}$ for $3 \mathrm{~min} ; 94^{\circ} \mathrm{C}$ for $1 \mathrm{~min}, 58^{\circ} \mathrm{C}$ for $1 \mathrm{~min}, 72{ }^{\circ} \mathrm{C}$ for $2 \mathrm{~min}, 30$ cycle process; $72{ }^{\circ} \mathrm{C}$ for $8 \mathrm{~min}$; $4{ }^{\circ} \mathrm{C}$ for $30 \mathrm{~min}$. The PCR products, which were electrophoresed with EB on $1 \%$ agarose gel whose each hole was filled by $5 \mu \mathrm{L}$ sample and $1 \mu \mathrm{L}$ loading buffer, run at $100 \mathrm{~V}$ for $30 \mathrm{~min}$ and visualize DNA fragments with UV light. Then, the PCR products were purified and sequenced by Invitrogen (in Shanghai China). To determine the closest relatives of $16 \mathrm{~S}$ rDNA partial sequence, the alignment search was performed with BLAST and GenBank databases to carry out sequence homology analysis. Phylogenetic tree was constructed by 
Neighbor-Joining method in MEGA 4.0 software (Tamura et al., 2007). Consensus sequence from each strain was generated by Sequencher program (version 4.7), using sequences of 29 Bacillus (GenBank Database) as reference strains and 1 Paenibacillus barcinonensis (DQ363432, GenBank Database) as comparison, to build the phylogenetic tree. Consensus sequences were aligned with Bacillus type strains using Clustal W (Thompson, Plewniak, \& Poch, 1999) from MEGA to construct the phylogenetic tree, by running Neighbor-Joining program with the Kimura (2007) correction and boot strapping for 1000 times.

\subsection{HHP on Bacterial Suspension of Bacillus}

Each identified Bacillus was inoculated to NA liquid culture medium (NA, composition: peptone $10.0 \mathrm{~g} / \mathrm{L}$, beef extract $3.0 \mathrm{~g} / \mathrm{L}, \mathrm{NaCl} 5.0 \mathrm{~g} / \mathrm{L}, \mathrm{pH} 7.2 \pm 0.2$, autoclaving at $121{ }^{\circ} \mathrm{C}$ for $20 \mathrm{~min}$ ), to being incubated at $37{ }^{\circ} \mathrm{C}$ for $48 \pm 2 \mathrm{~h}$, in order to maintain the ratio between vegetative mass and spores of Bacillus in 1:1. Then, precipitates gathered by centrifugation at $3000 \mathrm{r} / \mathrm{min}$ for $15 \mathrm{~min}$, were added to phosphate buffer $(0.03 \mathrm{~mol} / \mathrm{L}, \mathrm{pH} 7.2)$ in order to suspend.

Adjusting the initial concentration to $10^{7}-10^{8} \mathrm{CFU} / \mathrm{mL}$, bacterial suspension of Bacillus was dispensed and vacuum-packed by heat-sealed sterile polyethylene bags (10 ml/package, $-0.1 \mathrm{MPa}$ vacuum degree) under aseptic condition. Each bag of samples was HHP-treated at pressure level in 300-600 MPa for 3-25 min respectively, at room temperature.

\subsection{Enumeration of Viable Count}

$1.0 \mathrm{~mL}$ of each HHP-treated sample was immediately sucked into $9.0 \mathrm{~mL}$ sterile $0.85 \% \mathrm{NaCl}$ solution for dilution. Further serial dilutions were made for using pour plate technique to determine the viable count. Total aerobic mesophilic bacteria were enumerated on nutrient agar (NA) after incubation at $37^{\circ} \mathrm{C}$ for $48 \mathrm{~h}$.

The inactivation effect of Bacillus was assessed by taking LRV (Logarithmic Reduction Value, $-\log \left(\mathrm{N} / \mathrm{N}_{0}\right)$ ) as index, where colony counts of HHP-treated samples were recorded as $\mathrm{N}$, while the initial counts of microorganisms of untreated samples were recorded as $\mathrm{N}_{0}$.

\subsection{Statistical Analysis}

All data presented were means \pm standard value and the measure ments were done with three replicates for statistical validity. One-way analysis of variance (ANOVA) was performed to check the variability of data and validity of the results. The data were analyzed with the software Statistical Package for the Social Sciences (SPSS, Chicago, IL, USA) version 13.0 and the results were considered significant if $\mathrm{P}<0.05$.

\section{Result and Discussion}

\subsection{S rDNA Amplification and Sequencing}

Four bacterial strains were isolated from samples of Pickled Cowpea, were named MJJ-1, MJJ-7, MJJ-9 and MJJ-18. Under the condition of $1 \%$ agarose gel electrophoresis, their $16 \mathrm{~S}$ rDNA amplified and purified products were showed in electrophoresis images (Figure 1), which indicated that the specific bands of amplified products were about $1500 \mathrm{bp}$ according to the Marker band. Then the positive products which fragment lengths were about $1500 \mathrm{bp}$, were sent to Invitrogen (Shanghai) Co. Ltd. for the full length genome sequencing of 16S rDNA gene.

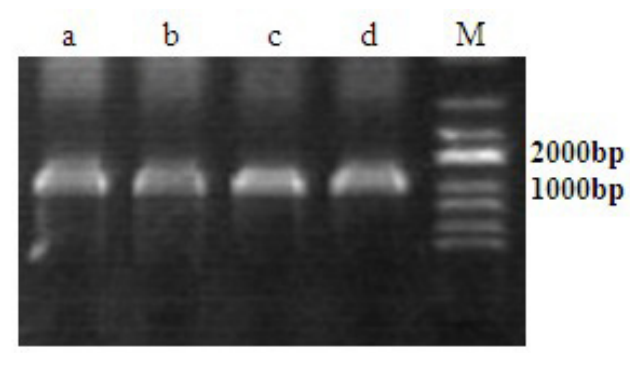

Figure 1.The electrophoresis images of 16s rDNA amplified and purified products. (a): MJJ1; (b): MJJ7; (c):MJJ9; (d): MJJ18; (M): DL2000 Marker

The full length genome sequences of the 4 strains had been submitted to NCBI/GenBank database. The accession number of strains MJJ-1, MJJ-7, MJJ-9 and MJJ-18 in GenBank were JQ837269, JQ837270, JQ837272 and JQ837271 respectively. The results of comparison indicated that all of them were Bacillus. 
Specifically, the sequence similarity threshold between MJJ-1 and Bacillus licheniformis reached $100 \%$. Meanwhile, the sequences of MJJ-7 and Bacillus subtilis, MJJ-9 and Bacillus sonorens also showed $100 \%$ similar degree, and the sequence similarity threshold between MJJ-18 and Bacillus pumilus was exceed 99\%.

\subsection{Analysis of Phylogenetic Tree}

Phylogenetic tree illuminated in Figure 2 showed the phylogenetic analysis on target strains' consensus sequences and reference sequences from 34 Bacillus and 1 Paenibacillus. With specific Bacillus reference strains, each target strain clusters into distinct species according to sequence similarity and homology analysis. MJJ-1 is classified as B. licheniformis, while MJJ-7 as B. subtilis, MJJ-9 as B. sonorensis, and MJJ-18 as B. pumilus.

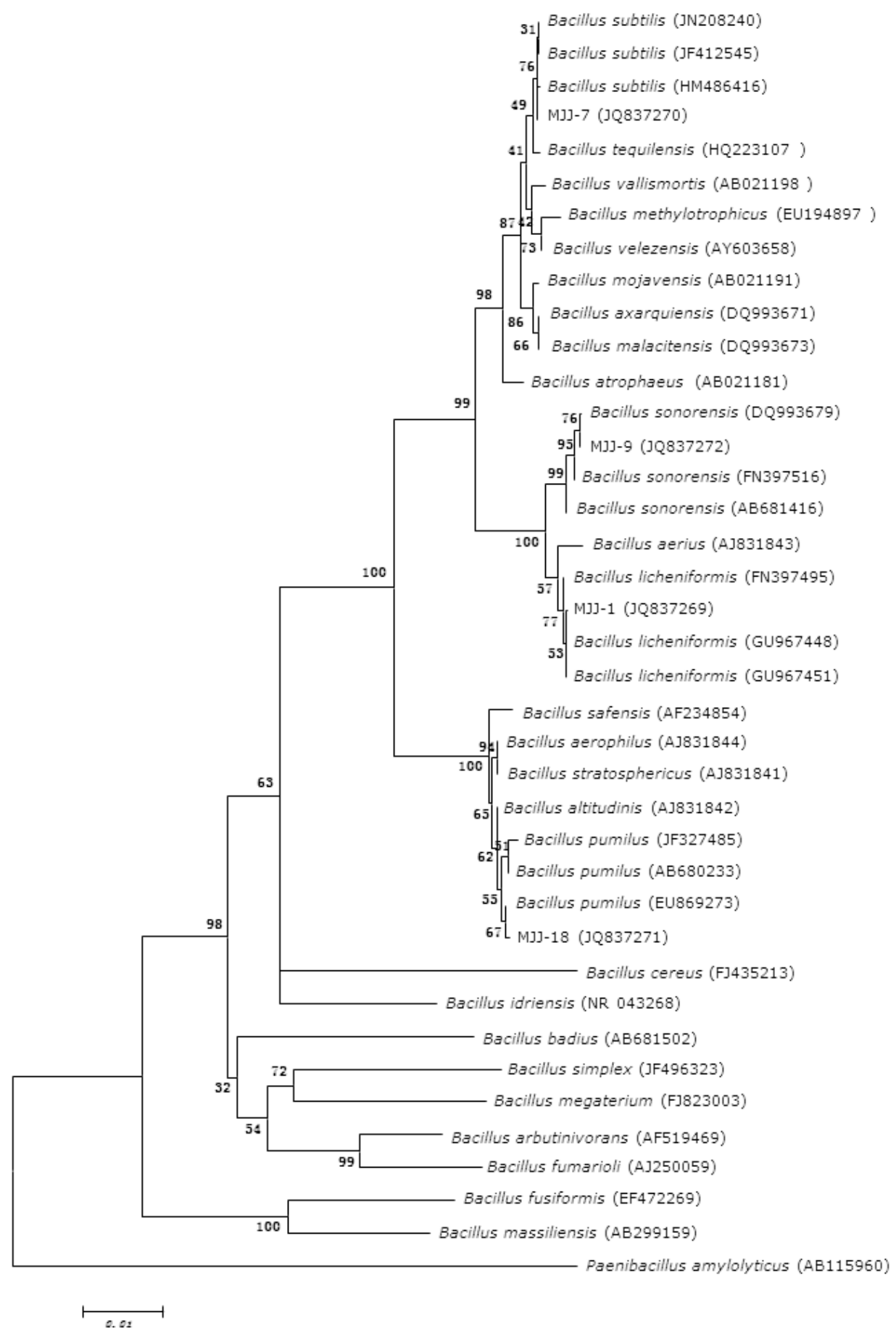

Figure 2. Phylogenetic tree of the strains isolated from Pickled cowpea by Neighbor-joining method of $16 \mathrm{~S}$ rDNA gene sequences 
Residuary baroduric bacteria, isolated from Pickled Cowpea in high pressure condition, and classified as Bacillus by $16 \mathrm{~S}$ rDNA sequence analysis. The result showed that the bacterial species isolated at HHP condition $600 \mathrm{MPa} / 25 \mathrm{~min}$ were identified as Bacillus $s p$, in accord with strains isolated from HHP-treated juice and mushroom (Jiang, Yin, Song, Yu, \& Chen, 2010; Hou et al., 2011; Xu et al., 2011). B. licheniformis, B. subtilis and $B$. pumilus had been isolated from previous studies on fermented products. Under common condition, B. pumilus was isolated from Kimchi (Yamanaka, Moriyoshi, Ohmoto, Ohe, \& Sakai, 2010); B. licheniformis, B. subtilis and B. pumilus were isolated from Pickle in Sichuan (Wang, 2010); B. subtilis and B. licheniformis were isolated from fermented bean products such as Korean Cheonggukjang, Indian Kinema and African Soumbala (Yamanaka et al., 2010; Kwon et al., 2009; Sarkar, Hasenack, \& Nout, 2002). Additionally, $\mathrm{He}$ et al.(2009) isolated and identified baroduric bacteria including B. subtilis and B. licheniformis from HHP-treated Low Acid Canned under $600 \mathrm{MPa}$ condition, while B. licheniformis and B. pumilus were identified as pressure-resistant bacteria from Strawberry Pulp under the same pressure level (Zhang, 2010). Meanwhile, isolation of $B$. sonorentsis from fermented products has not been reported.

\subsection{Inactivation of Baroduric Bacteria}

Based on inactivation under different pressure levels and different pressure holding time (Table 1), Figure 3 and Figure 4 were extracted with different emphasizes on pressure and time.

Table 1. Effect of pressure levels and pressure holding time on inactivation of pressure treated baroduric bacteria $\left(\log _{10} \mathrm{CFU} / \mathrm{mL}\right)$. Different letters show significant difference at $\mathrm{P}<0.05$ ( \pm Standard deviation)

\begin{tabular}{|c|c|c|c|c|c|c|c|c|c|}
\hline \multirow{2}{*}{ Strains } & \multirow{2}{*}{ Pressure } & \multicolumn{8}{|c|}{ Pressure holding time } \\
\hline & & Untreated & $3 \min$ & $5 \mathrm{~min}$ & $8 \min$ & $10 \mathrm{~min}$ & $15 \mathrm{~min}$ & $20 \mathrm{~min}$ & $25 \mathrm{~min}$ \\
\hline \multirow[t]{4}{*}{ B.licheniformis } & $300 \mathrm{MPa}$ & $7.62 \pm 0.18^{\mathrm{a}}$ & $4.95 \pm 0.09^{b}$ & $4.53 \pm 0.08^{\mathrm{b}}$ & $4.47 \pm 0.13^{\mathrm{b}}$ & $4.32 \pm 0.10^{\mathrm{b}}$ & $3.76 \pm 0.08^{\mathrm{c}}$ & $3.51 \pm 0.07^{\mathrm{c}}$ & $3.51 \pm 0.09^{\mathrm{c}}$ \\
\hline & $400 \mathrm{MPa}$ & $7.62 \pm 0.09^{\mathrm{a}}$ & $3.85 \pm 0.09^{\mathrm{b}}$ & $3.57 \pm 0.05^{\mathrm{b}}$ & $3.54 \pm 0.10^{\mathrm{b}}$ & $3.45 \pm 0.09^{\mathrm{bc}}$ & $3.22 \pm 0.11^{\mathrm{c}}$ & $2.96 \pm 0.07^{\mathrm{c}}$ & $2.94 \pm 0.08^{\mathrm{c}}$ \\
\hline & $500 \mathrm{MPa}$ & $7.70 \pm 0.09^{\mathrm{a}}$ & $3.80 \pm 0.10^{\mathrm{b}}$ & $3.23 \pm 0.14^{\mathrm{b}}$ & $3.20 \pm 0.10^{\mathrm{b}}$ & $3.10 \pm 0.09^{c}$ & $2.91 \pm 0.08^{\mathrm{c}}$ & $2.87 \pm 0.08^{\mathrm{c}}$ & $2.85 \pm 0.11^{\mathrm{c}}$ \\
\hline & $600 \mathrm{MPa}$ & $7.70 \pm 0.09^{\mathrm{a}}$ & $3.65 \pm 0.12^{\mathrm{b}}$ & $3.07 \pm 0.09^{\mathrm{bc}}$ & $3.03 \pm 0.06^{\mathrm{c}}$ & $2.93 \pm 0.09^{\mathrm{cd}}$ & $2.73 \pm 0.05^{\mathrm{d}}$ & $2.71 \pm 0.09^{\mathrm{d}}$ & $2.68 \pm 0.09^{\mathrm{e}}$ \\
\hline \multirow[t]{4}{*}{ B. subtilis } & $300 \mathrm{MPa}$ & $8.70 \pm 0.09^{\mathrm{a}}$ & $6.10 \pm 0.10^{\mathrm{b}}$ & $5.71 \pm 0.06^{\mathrm{b}}$ & $5.64 \pm 0.13^{\mathrm{b}}$ & $5.54 \pm 0.09^{b}$ & $5.20 \pm 0.10^{\mathrm{c}}$ & $4.81 \pm 0.07^{\mathrm{c}}$ & $4.80 \pm 0.08^{\mathrm{c}}$ \\
\hline & $400 \mathrm{MPa}$ & $8.70 \pm 0.09^{\mathrm{a}}$ & $5.40 \pm 0.08^{\mathrm{b}}$ & $4.93 \pm 0.07^{\mathrm{b}}$ & $4.60 \pm 0.05^{\mathrm{b}}$ & $4.46 \pm 0.10^{\mathrm{c}}$ & $4.41 \pm 0.09^{\mathrm{c}}$ & $4.33 \pm 0.09^{\mathrm{c}}$ & $4.27 \pm 0.08^{\mathrm{d}}$ \\
\hline & $500 \mathrm{MPa}$ & $8.76 \pm 0.09^{\mathrm{a}}$ & $4.28 \pm 0.05^{\mathrm{b}}$ & $3.91 \pm 0.09^{\mathrm{b}}$ & $3.74 \pm 0.10^{\mathrm{bc}}$ & $3.54 \pm 0.08^{\mathrm{c}}$ & $3.37 \pm 0.06^{\mathrm{c}}$ & $3.33 \pm 0.10^{\mathrm{d}}$ & $3.32 \pm 0.07^{\mathrm{d}}$ \\
\hline & $600 \mathrm{MPa}$ & $8.62 \pm 0.09^{\mathrm{a}}$ & $3.72 \pm 0.07^{\mathrm{b}}$ & $3.32 \pm 0.07^{\mathrm{b}}$ & $3.28 \pm 0.06^{\mathrm{c}}$ & $3.16 \pm 0.05^{\mathrm{c}}$ & $3.11 \pm 0.13^{\mathrm{d}}$ & $3.09 \pm 0.11^{\mathrm{d}}$ & $3.06 \pm 0.07^{\mathrm{e}}$ \\
\hline \multirow[t]{4}{*}{ B. pumilus } & $300 \mathrm{MPa}$ & $7.78 \pm 0.09^{\mathrm{a}}$ & $5.98 \pm 0.06^{\mathrm{b}}$ & $5.77 \pm 0.08^{\mathrm{b}}$ & $5.75 \pm 0.08^{\mathrm{b}}$ & $5.72 \pm 0.05^{\mathrm{b}}$ & $5.46 \pm 0.10^{\mathrm{c}}$ & $5.20 \pm 0.09^{\mathrm{d}}$ & $5.19 \pm 0.07^{\mathrm{d}}$ \\
\hline & $400 \mathrm{MPa}$ & $7.84 \pm 0.09^{\mathrm{a}}$ & $5.22 \pm 0.08^{\mathrm{b}}$ & $4.92 \pm 0.08^{\mathrm{b}}$ & $4.78 \pm 0.09^{\mathrm{c}}$ & $4.60 \pm 0.07^{\mathrm{c}}$ & $4.37 \pm 0.09^{\mathrm{d}}$ & $4.03 \pm 0.08^{\mathrm{d}}$ & $4.01 \pm 0.08^{\mathrm{d}}$ \\
\hline & $500 \mathrm{MPa}$ & $7.84 \pm 0.09^{\mathrm{a}}$ & $4.17 \pm 0.05^{\mathrm{b}}$ & $3.80 \pm 0.09^{b}$ & $3.72 \pm 0.07^{\mathrm{c}}$ & $3.62 \pm 0.06^{\mathrm{c}}$ & $3.27 \pm 0.07^{\mathrm{d}}$ & $3.23 \pm 0.10^{\mathrm{d}}$ & $3.21 \pm 0.07^{\mathrm{d}}$ \\
\hline & $600 \mathrm{MPa}$ & $7.73 \pm 0.09^{\mathrm{a}}$ & $3.75 \pm 0.06^{\mathrm{b}}$ & $3.13 \pm 0.08^{\mathrm{c}}$ & $3.07 \pm 0.07^{\mathrm{cd}}$ & $3.03 \pm 0.05^{\mathrm{d}}$ & $2.85 \pm 0.09^{\mathrm{d}}$ & $2.82 \pm 0.08^{\mathrm{e}}$ & $2.80 \pm 0.07^{\mathrm{e}}$ \\
\hline \multirow[t]{4}{*}{ B. sonorentsis } & $300 \mathrm{MPa}$ & $8.49 \pm 0.09^{\mathrm{a}}$ & $6.13 \pm 0.06^{\mathrm{b}}$ & $5.69 \pm 0.08^{\mathrm{c}}$ & $5.66 \pm 0.10^{\mathrm{c}}$ & $5.60 \pm 0.09^{\mathrm{c}}$ & $5.51 \pm 0.10^{\mathrm{c}}$ & $5.34 \pm 0.05^{\mathrm{d}}$ & $5.31 \pm 0.07^{\mathrm{d}}$ \\
\hline & $400 \mathrm{MPa}$ & $8.20 \pm 0.06^{\mathrm{a}}$ & $5.11 \pm 0.06^{\mathrm{b}}$ & $4.55 \pm 0.06^{\mathrm{c}}$ & $4.46 \pm 0.08^{\mathrm{c}}$ & $4.31 \pm 0.07^{\mathrm{cd}}$ & $4.03 \pm 0.10^{\mathrm{d}}$ & $3.58 \pm 0.07^{\mathrm{d}}$ & $3.57 \pm 0.07^{\mathrm{d}}$ \\
\hline & $500 \mathrm{MPa}$ & $8.25 \pm 0.09^{\mathrm{a}}$ & $4.13 \pm 0.09^{b}$ & $3.60 \pm 0.07^{\mathrm{b}}$ & $3.47 \pm 0.10^{\mathrm{c}}$ & $3.40 \pm 0.07^{\mathrm{c}}$ & $3.11 \pm 0.06^{\mathrm{d}}$ & $3.07 \pm 0.11^{\mathrm{d}}$ & $3.06 \pm 0.08^{\mathrm{d}}$ \\
\hline & $600 \mathrm{MPa}$ & $8.33 \pm 0.09^{\mathrm{a}}$ & $3.75 \pm 0.09^{\mathrm{b}}$ & $3.32 \pm 0.06^{\mathrm{c}}$ & $3.29 \pm 0.09^{c}$ & $3.23 \pm 0.07^{\mathrm{d}}$ & $3.04 \pm 0.10^{\mathrm{e}}$ & $3.03 \pm 0.07^{\mathrm{e}}$ & $3.04 \pm 0.08^{\mathrm{e}}$ \\
\hline
\end{tabular}

The effects of pressure levels and pressure holding time on the inactivation of 4 Bacillus were presented in Figure 3. The inactivation curves of 4 Bacillus are similar, that the increasing rate of each LRV of bacterial colony changes as 4 period: great level in the first few minutes, lower level in the following minutes, then increases for a while, after that falls to 0 . During the $1^{\text {st }}$ and $2^{\text {nd }}$ period, at each pressure level, inactivation curves increases probably because of death of the vegetative mass of Bacillus. In the 3rd period, increasing rate of LRV increases probably because of death of spores. The assumption is demonstrated by studies. The inactivation curves of vegetative mass of B. licheniformis and B. subtilis won't change at pressure level from $300 \mathrm{MPa}$ to $500 \mathrm{MPa}$ after $10 \mathrm{~min}$, while inactivation curves of spores grows until $20 \mathrm{~min}$ (He et al., 2009). Though mechanism of inactivation is unproved yet, it was strongly supported by effect on microorganism 
caused by HHP, including cell rupture, cytoplasm disorder, cytoplasm leak, and denaturation of protein, enzyme and nucleic acid (Zeng et al., 2006; Wuytack \& Michiels, 2001; Smelt, 1998). The higher pressure resistance of spore wall restrains inactivation caused by HHP, and extends the time of inactivation of spores. As a result, the inactivation curves display two increasing stages. The vegetative cell of bacteria, mycete and saccharomycetes were inactivated at 200-600 MPa pressure at ambient temperature (Smelt, 1998), while some spores can survive under $1200 \mathrm{MPa}$ pressure (Gould, 2001). Pressure resistance of spore wall could be diminished by auxiliary method, such as mild heat and bacteriostat, to impel germination of spores (Vercammen, Vivijs, Lurquin, \& Michiels, 2012; Hang, 2012).
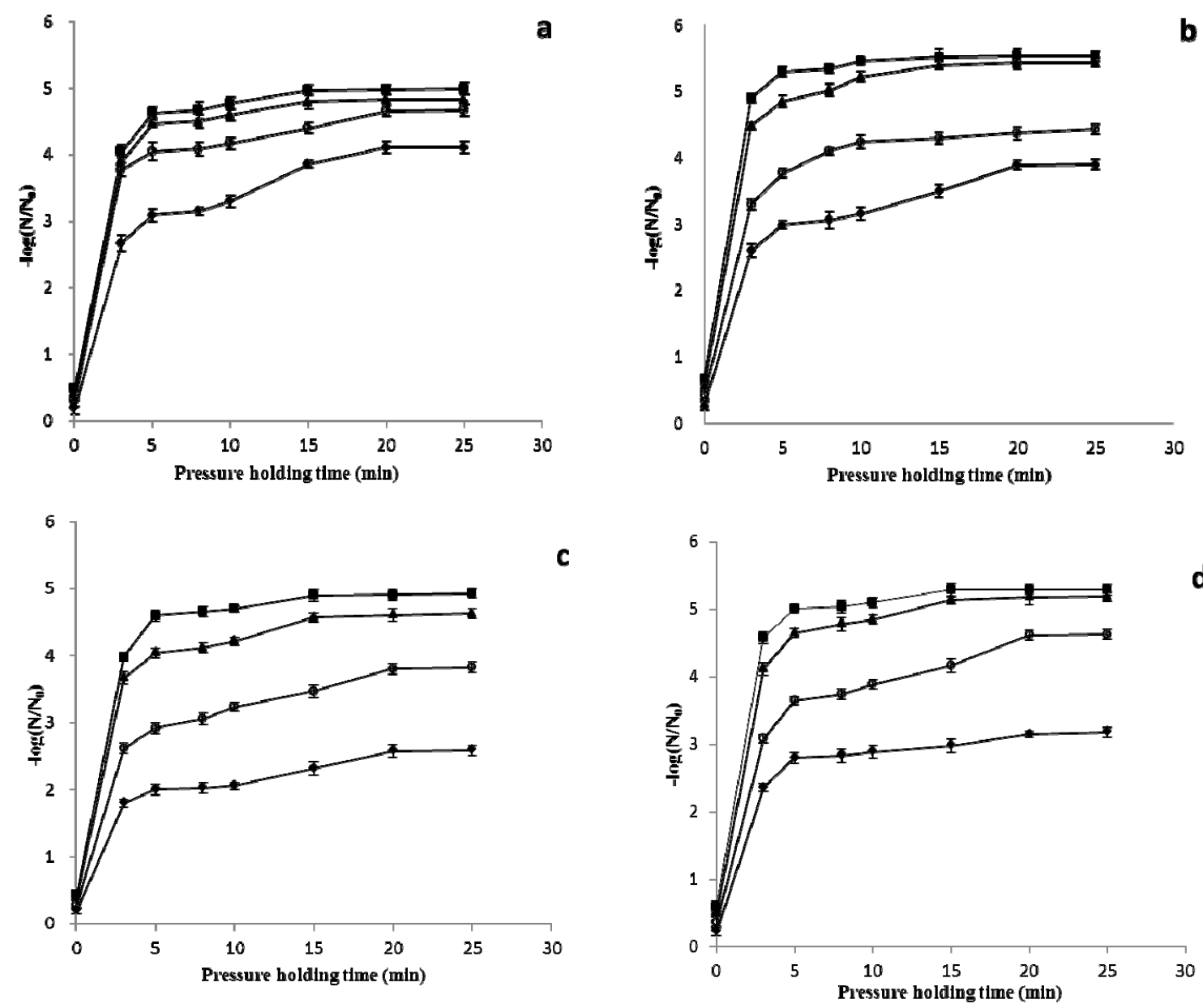

Figure 3. Inactivation curves for 4 Bacillus in phosphate buffer, subjected to various pressure (300 to $600 \mathrm{MPa})$. a: B. licheniformis, b: B. subtilis, c: B. pumilus, d: B. sonorensis.; (ロ) $600 \mathrm{MPa}$, ( $\mathbf{\Delta}) 500 \mathrm{MPa}$, (०) $400 \mathrm{MPa}$ and $(\diamond) 300 \mathrm{MPa}$ 

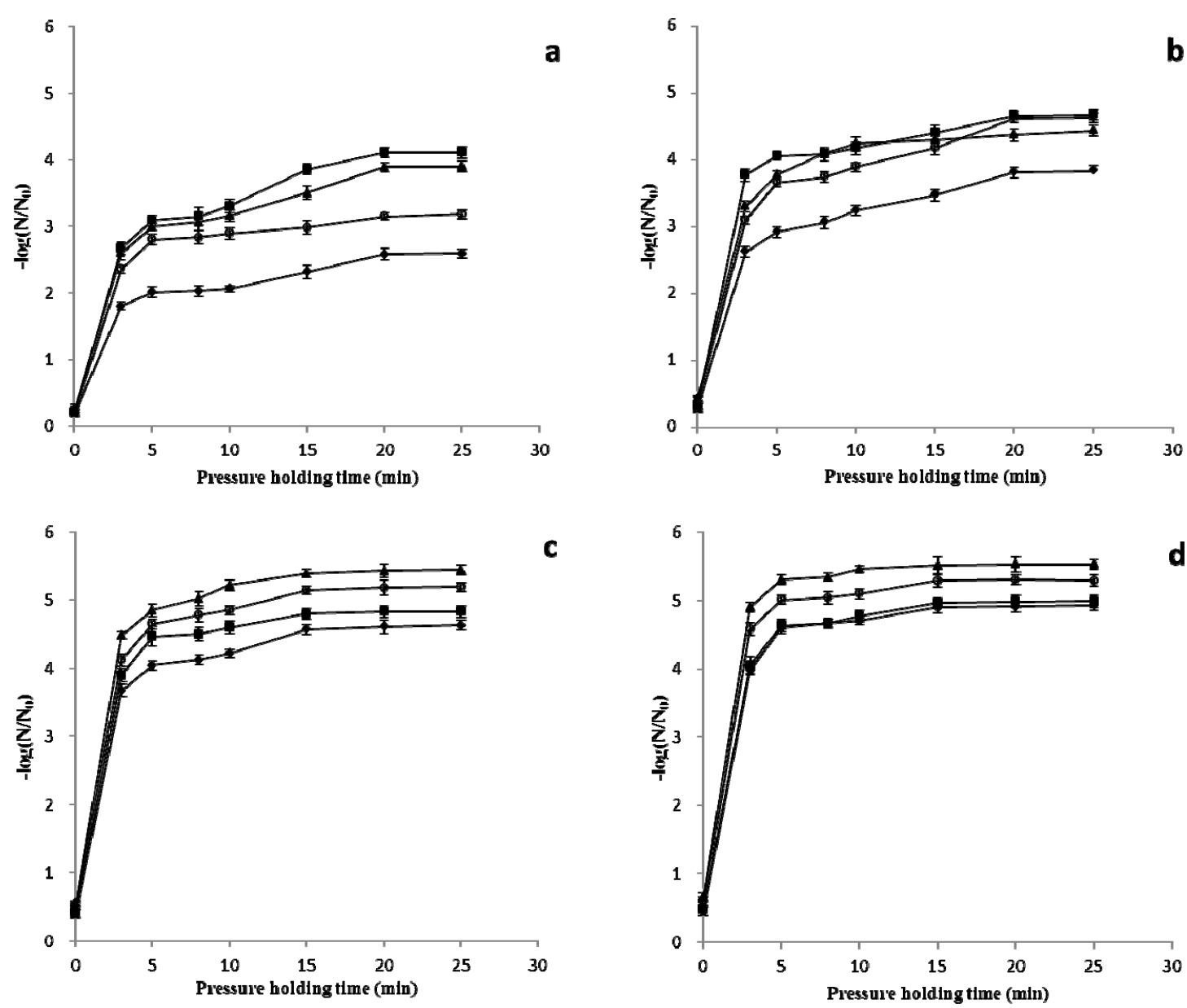

Figure 4. Inactivation curves for 4 Bacillus in phosphate buffer, subjected to various processing time (0 to 25

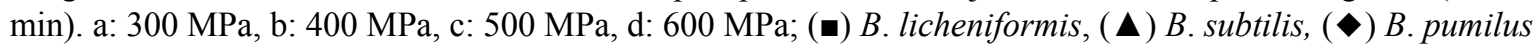
and (०) B. sonorens

\subsection{Influence to Inactivation from Pressure Levels}

The inactivation curves of each strain under different pressure conditions were reflected respectively in Figure 3. Within the range of experimental conditions studied, the results showed that survivor counts of Bacillus significantly declined along with increasing pressure $(\mathrm{P}<0.05)$. The LRVs of bacterial colony of $B$. subtilis at $300 \mathrm{MPa}, 400 \mathrm{MPa}, 500 \mathrm{MPa}$ and $600 \mathrm{MPa}$ for 15 min were $3.50 \log , 4.29 \log , 5.39 \log$ and 5.51 $\log$ (Figure 3b). Similarly, the LRVs of B. sonorensis for $20 \mathrm{~min}$ pressure holding time were $3.15 \mathrm{log}, 4.62 \mathrm{log}$, $5.18 \log$ and $5.30 \log$ (Figure 3d). Both of them showed that LRV increased with increasing pressure level.

However, the ratio between increasing rate of LRV and increasing rate of pressure decreased while pressure level was increasing, no matter which Bacillus is focused. For instance, under 15 min pressure holding time, the LRV of B. sonorensis relatively declined $1.19 \log$ when pressure level increased from $300 \mathrm{MPa}$ to 400 $\mathrm{MPa}$, whereas it relatively dipped $0.97 \log$ when pressure level increased from $400 \mathrm{MPa}$ to $500 \mathrm{MPa}$, and it relatively decreased $0.15 \mathrm{log}$ when pressure level increased from $500 \mathrm{MPa}$ to $600 \mathrm{MPa}$ (Figure 3d). Therefore, it can infer that the upper bound of LRV exists, when pressure is greater than some threshold, LRV won't increased along with increasing of pressure. Because of the limitation of experimental equipment, the threshold pressure of each Bacillus had not been observed yet in this study. Previous research proved that the LRV upper bound and pressure threshold exist under fixed condition, but they changed when different condition was applied, such as different temperature (Reddy et al., 1999).

On the other hand, the differences of LRV of $B$. licheniformis between adjacent pressure levels were minimal among 4 Bacillus, while the differences of LRV of B. pumilus were maximal. The LRV of B. licheniformis at $300 \mathrm{MPa}, 400 \mathrm{MPa}, 500 \mathrm{MPa}$ and $600 \mathrm{MPa}$ with $10 \mathrm{~min}$ pressure holding time were $3.30 \log , 4.17 \log , 4.60$ 
$\log$ and $4.77 \log$. They increased to $4.11 \log , 4.68 \log , 4.85 \log$ and $5.02 \log$ when pressure holding time increased to $25 \mathrm{~min}$ (Figure 3a). On contrary, the LRV of bacterial colonyof B. pumilus at pressure level from $300 \mathrm{MPa}$ to $600 \mathrm{MPa}$ with $10 \mathrm{~min}$ holding time were $2.06 \log , 3.24 \log , 4.22 \log$ and $4.70 \mathrm{log}$, while they were $2.59 \mathrm{log}, 3.83 \mathrm{log}, 4.63 \mathrm{log}$ and $4.93 \mathrm{log}$ with $25 \mathrm{~min}$ pressure holding time (Figure 3c). The probable reason was that sensitivity of vegetative mass and spores of diverse Bacillus species were different.

Difference of pressure resistance among 4 Bacillus at same pressure level and different processing holding time was described in Figure 4. The result of intuitionistic analysis in Figure $4 \mathrm{a}$ and Figure $4 \mathrm{~b}$ showed that the pressure resistance at 300-400 MPa pressure level was ranked as $B$. pumilus $>B$. sonorensis $>B$. subtilis $>B$. licheniformis. After that, the order was changed to B. pumilus $>B$. licheniformis $>B$. sonorensis $>$ B. subtilis at 500-600 MPa pressure range (Figure 4c and Figure 4d). Compare with other 3 Bacillus, B. licheniformis displayed more sensitivity to pressure at 300-400 MPa pressure range and LRV of bacterial colony relatively increased rapidly with pressure holding time prolonging, whereas it showed pressure resistance that was second to B. pumilus when pressure level increased to $500 \mathrm{MPa}$ or $600 \mathrm{MPa}$. Under 300-600 MPa pressure condition for varied holding time, B. pumilus always kept the greatest pressure resistance among 4 Bacillus identified from Pickled Cowpea. Therefore, it could been selected as the indicator bacteria of Pickled Cowpea for HHP treatment, and the result could provide the theory basis for research on HHP technology of Pickle.

\subsection{Influence to Inactivation from Holding Time}

Inactivation of HHP-treated bacteria consists of two parts, death caused by instantaneous pressure and subsequent destruction during the pressure holding time (Basak, Ramaswamy, \& Piette, 2002). Instantaneous inactivation due to pressurization-depressurization process without holding time while pressure just attains the target value, and its effectiveness depends on pressure levels, the impact obviously increases with increasing pressure.

According to Figure 2, inactivation of Bacillus was sensitive to the level of instantaneous pressure. LRV of bacterial colony of B. subtilis were $0.26 \log , 0.42 \log , 0.56 \log$ and $0.67 \log$ on $300 \mathrm{MPa}, 400 \mathrm{MPa}, 500 \mathrm{MPa}$ and $600 \mathrm{MPa}$ pressure condition, while that of $B$. sonorensis were $0.23 \log , 0.36 \log , 0.51 \log$ and $0.60 \log$ at the same pressure condition. By contrast, instantaneous inactivation of B. licheniformis and B. pumilus were relatively small, LRV of bacterial colony were $0.49 \log$ and $0.45 \log$ under $600 \mathrm{MPa}$ pressure respectively. It probably indicated $B$. subtilis and $B$. sonorensis are more sensitive to instantaneous pressure than $B$. licheniformis and B. pumilus.

During the whole pressure holding time, the period in which bacterial colony changes is named effective pressure holding time. Figure 4 showed that the length of effective pressure holding time of 4 Bacillus was similar, and decreased with increasing pressure level $(\mathrm{P}<0.05)$. Bacterial colony no longer changed at 300 MPa after approximate $20 \mathrm{~min}$ pressure holding time (Figure 4a). Hence, the effective pressure holding time was $20 \mathrm{~min}$. The rate of inactivation was more rapid at $400 \mathrm{MPa}$ than that at $300 \mathrm{MPa}$ during the same pressure holding time, but effective pressure holding time under both pressure levels was same (Figure $4 \mathrm{~b}$ ). However, Figure $4 \mathrm{c}$ and Figure $4 \mathrm{~d}$ indicated that the effective pressure holding time was reduced to $15 \mathrm{~min}$ at 500-600 MPa pressure level. The sterilizing effect cannot be improved through merely extend pressure holding time, when longer than effective pressure holding time (Nakayama \& Yano, 1996).

\section{Conclusions}

Though famous in the world, consumption of Pickle is greatly limited by the lack of preservation technology, because its special flavor and nutrient substance are easily destroyed by traditional thermal sterilization methods. In this study, HHP-treated Pickled Cowpea was analyzed, from which 4 baroduric bacteria were isolated and all of them were identified as Bacillus $s p$ by $16 \mathrm{~S}$ rDNA gene sequence technology. Inactivation of the 4 baroduric bacteria under different pressure levels and different pressure holding time is studied, to investigate the feasibility of HHP technology on preservation of Pickle industry.

The result indicated that pressure level and pressure holding time can significant impact on inactivation of Bacillus. Instantaneous pressure affects inactivation of Bacillus respectively. B. subtilis is more sensitive to instantaneous pressure than others according to LRV curve. Furthermore, during effective pressure holding time, LRV of each bacterial colony increased rapidly at first, which expressed massive death of Bacillus, and then the increasing rate of inactivation decreased. The 4 Bacillus presented varied pressure resistance under same pressure level. It was ranked as B. pumilus $>B$. sonorensis $>$ B. subtilis $>$ B. licheniformis under 300-400 MPa pressure, while the order changed to B. pumilus $>B$. licheniformis. $>B$. sonorensis $>$ B.subtilis under 500-600 MPa pressure. Since B. pumilus has higher pressure resistance in both stages, it is selected as the indicator bacteria for applying HHP treatment to Pickle production. 
The future work including, firstly, inactivation of vegetative mass and spores of the 4 Bacillus by HHP-treated will be investigated respectively to present their inactivate effect under different pressure level and holding time condition, to establish kinetic models of inactivation; secondly, because spores have higher pressure resistance, effect of HHP with assistant methods, such as moderate heat and inartificial bacteriostat, should be studied.

\section{Acknowledgement}

The research was supported by the Project of National Natural Science Foundation of China (No.31171726) and the Technology Support Project of Sichuan Province (No.2010NZ0045)

\section{References}

Anne, Vercammen, Bram, Vivijs, IneLurquin, \& Chris, W. Michiels. (2012). Germination and inactivation of Bacillus coagulans and Alicyclobacillusacidoterrestris spores by high hydrostatic pressure treatment in buffer and tomato sauce. International Journal of Food Microbiology, 152, 162-167. http://dx.doi.org/10.1016/j.ijfoodmicro.2011.02.019

Basak, S., Ramaswamy, H. S., \& Piette, J. P. G. (2002). High pressure destruction kinetics of Leuconostocmesenteroides and Saccharomyces cerevisiae in single strength and concentrated orange juice. Innovative Food Science and Emerging Technologies, 3(3), 223-231. http://dx.doi.org/10.1016/S1466-8564(02)00008-5

Cheigh, H., \& Park, K. (1994). Biochemical microbiological and nutritional aspects of kimchi (Korean fermented vegetable products). Crit Rev Food SciNutr, 34(2), 175-203. http://dx.doi.org/10.1080/10408399409527656

Gould, G. W. (2001). New processing technologies: an overview. Proceedings of the Nutrition Society, 60(4), 463-474. http://dx.doi.org/10.1079/PNS2001105

Gun-Hee, Kwon, Hwang-A, Lee, et al. (2009). Development of a RAPD-PCR method for identification of Bacillus species isolated from Cheonggukjang. International Journal of Food Microbiology, 129(3), 282-287. http://dx.doi.org/10.1016/j.ijfoodmicro.2008.12.013

Hang, Y. Y. (2012). Effect of Ultra-high Pressure Combined with Tea Polyphenols Treatments on Bacillus Subtilis. Journal of Qiongzhou University, 18(2), 41-44.

Hartmann, C., Mathmann, K., \& Delgado, A. (2006). Mechanical stresses in cellular structures under high hydrostatic pressure. Innovative Food Science \& Emerging Technologies, 7(1), 1-12. http://dx.doi.org/10.1016/j.ifset.2005.06.005

He, H. Y., Qian, P., Lu, R. R., Yu, J. Y., Chen, Wi, Zhao, J. X., et al. (2009) Inactivation of Spoilage in Low Acid Canned by High Pressure Processing. Food and Fermentation Industries, 35(6), 18-22.

Hou, Y, et al. (2011). Isolation and Identification of a Spoilage Bacteria in the Ultra-high Pressure Preserved Lentinulaedodes Foods. Journal of Anhui Agri.Sci, 39(28), 17563-17565.

Jiang, H. R., Yin, L. L., Song, L. J., Yu, X. Y., \& Chen, J. L. (2010). A Research into the Lethal Effect of Bacillus sp. Isolated and Identified from Fresh Hami Melon Juice with high Hydrostatic Pressure Treatment. Journal of Shihezi University (Natural Science), 28(1), 91-94.

Jin, H. J., Tu, R., Xu, F., et al. (2011). Identification of nitrogen-fixing Paenibacillus from different plant rhizospheres and a novel nifH gene detected in P.stellifer. Microbiology, 80(1), 117-124. http://dx.doi.org/10.1134/S0026261711010097

Kuribayashi, T., Ohsawa, K., Takanami, S., et al. (1996). High pressure treatment for Nozawana-zuke (salted vegetables) preservation. Progress in Biotechnology, 13, 397-400. http://dx.doi.org/10.1016/S0921-0423(06)80067-5

Meyer, R. S., Cooper, K. L., Knorr, D., et al. (2000). High-pressure sterilization of foods. Food Technology, 54(11), 67-72.

Nakayama, A., \& Yano, Y. (1996). Comparison of pressure resistances of spores of six Bacillus strains with their heat resistances. Applied and Environmental Microbiology, 62(10), 3897-3900.

Peñas, E., Frias, J., Gomez, R., et al. (2010). High hydrostatic pressure can improve the microbial quality of $\begin{array}{lllll}\text { sauerkraut during } & \text { storage. }\end{array}$ http://dx.doi.org/10.1016/j.foodcont.2009.08.001 
Reddy, N. R., Solomon, H. M., Fingerhut, G. A., et al. (1999). Inactivation of clostridium botulinum type E spores by high pressure processing. Journal of Food Safety, 19(4), 277-288. http://dx.doi.org/10.1111/j.1745-4565.1999.tb00252.x

Sarkar, P. K., Hasenack, B., \& Nout, M. J. R. (2002). Diversity and functionality of Bacillus and related genera isolated from spontaneously fermented soybeans (Indian Kinema) and locust beans (African Soumbala). International Journal of Food Microbiology, 77(3), 175-186. http://dx.doi.org/10.1016/S0168-1605(02)00124-1

Smelt, J. P. P. M. (1998). Recent advances in the microbiology of high pressure processing. Trends in Food Science\&Technology, 9, 152-158. http://dx.doi.org/10.1016/S0924-2244(98)00030-2

Sohn, K., \& Lee, H. (1998). Effects of high pressure treatment on the quality and storage of kimchi. International Journal of Food Science \& Technology, 33(4), 359-365. http://dx.doi.org/10.1046/j.1365-2621.1998.00138.x

Song, H., Kim, D., Yook, H., et al. (2004). Application of gamma irradiation for aging control and improvement of shelf-life of kimchi, korean salted and fermented vegetables. Radiation Physics and Chemistry, 71(1), 57-60. http://dx.doi.org/10.1016/j.radphyschem.2004.04.005

Tamura, K., Dudley, J., Nei, M., et al. (2007). MEGA: Molecular Evolutionary Genetics Analysis(MEGA) Software Version 4.0. Mol. Niol. Evol, 24(8), 1596-1599. http://dx.doi.org/10.1093/molbev/msm092

Thompson, J. D., Plewniak, F., \& Poch, O. (1999). A comprehensive comparison of multiple sequence alignment programs. Nucleic Acids Research, 27(13), 12682-2690. http://dx.doi.org/10.1093/nar/27.13.2682

Trujillo, A. J., Capellas, M., Buffa, M., et al. (2000). Application of high pressure treatment for cheese production. Food Research International, 311-316. http://dx.doi.org/10.1016/S0963-9969(00)00042-9

Wang, Y. Y. (2010). Isolation and Identification by 16S rDNA Sequence Analysis of Bacillus from Naturally Fermented Congee and Pickle. Inner Mongolia Agricultural University.

Wu, J. Z., Yu, X. L., \& Li, X. Y. (1999). Study on extending the shelf life of Pickled vegetables. Food and fermentation industries, 25(03), 39-42.

Wuytack, E. Y., \& Michiels, C. W. (2001). A study on the effects of high pressure and heat on Bacillus subtilis spores at low pH. Int J Food Microbiol, 64, 333-341. http://dx.doi.org/10.1016/S0168-1605(00)00478-5

$\mathrm{Xu}$, F., Liu, Y., Zhao, S., et al. (2011). Isolation of a Bacillus Strain from Packaged Pleurotusgeesterani Fruit Bodies Processed Using Super High Pressure Technology. ActaEdulis Fungi, 18(1), 59-62.

Yamanaka, H., Moriyoshi, K, Ohmoto, T., Ohe, T., \& Sakai, K. (2010). Degradation of bisphenol A by Bacillus pumilus isolated from kimchi,a traditionally fermented food. EurAsia J BioSci, 4, 33-40.

Yang, J. B, et al. (1996). Lactobacillus-Basic and Aapplication of Biology.China Light Industry Press.

Zeng, Q. M., Xie, H. M., Pan, J., Yang, Y., Xu, H. Q., Huang, X. D., \& Zhao, Y. N. (2006). Effect of Ultra-High Pressure Processing (UHPP) on the Microstructure of Bacillus subtilis. Chinese Journal of High Pressure Physics, 20(1), 83-87.

Zhang, L. Y. (2010). Isolation and Identification of Pressure-resistant Bacteria in Strawberry Pulp. China Agricultural University.

Zhong, X. M., Li, L., \& Xu, X. L. (2008). Application of HACCP system in Pickel production. Food Research and Development, 29(9), 147-150. 